\title{
Once-weekly epoetin beta is highly effective in treating anaemic patients with lymphoproliferative malignancy and defective endogenous erythropoietin production
}

\author{
Mario Cazzola, ${ }^{1}$ Yves Beguin, ${ }^{2}$ Janusz Kloczko, ${ }^{3}$ Ivan Spicka ${ }^{4}$ and Bertrand Coiffier ${ }^{5}{ }^{1}$ Division of \\ Haematology, University of Pavia Medical School and Istituto di Ricovero e Cura a Carattere Scientifico (IRCCS) \\ Policlinico S. Matteo, Pavia, Italy, ${ }^{2}$ Department of Haematology, University of Liège, CHU Sart-Tilman, Liège, Belgium, \\ ${ }^{3}$ Department of Haematology, Medical University, Bialystok, Poland, ${ }^{4}$ Division of Haematology, Charles University, \\ Prague, Czech Republic, and ${ }^{5}$ Service d'Hématologie, Centre Hospitalier Lyon-Sud, Pierre Bénite Cedex, France
}

Received 27 February 2003; accepted for publication 31 March 2003

\begin{abstract}
Summary. Epoetin beta, three-times weekly (t.i.w.), is effective in reversing anaemia in lymphoproliferative disorders. The current study investigated whether an epoetin beta dose of $30000 \mathrm{IU}$ given subcutaneously once weekly (q.w.) was at least as effective as 10000 t.i.w. administration in anaemic patients with lymphoproliferative malignancy and defective endogenous erythropoietin (Epo) production. Overall, 241 anaemic patients with multiple myeloma, low-grade non-Hodgkin's lymphoma or chronic lymphocytic leukaemia, all with serum Epo values $\leq 100 \mathrm{mU} / \mathrm{ml}$, were randomized to receive the q.w. $(n=119)$ or t.i.w. $(n=122)$ regimen for 16 weeks. The primary efficacy criterion, i.e. the time-adjusted area under the haemoglobin-time curve from weeks 5-16, was comparable between the q.w. and t.i.w. groups [differ-
\end{abstract}

ence $=-0 \cdot 20 \mathrm{~g} / \mathrm{dl}(90 \%$ confidence interval $-0 \cdot 52-0 \cdot 11)]$. Moreover, response rates were high and similar in both arms $(72 \%$ vs $75 \%$, q.w. and t.i.w. groups respectively). Baseline serum Epo was predictive of response: the lower serum Epo, the higher the likelihood of response $(P=0.002)$. Thus, epoetin beta administered q.w. is an effective and convenient treatment for anaemia in patients with lymphoproliferative disorders. Tailoring this treatment modality to subjects with defective endogenous Epo production represents a rational use of epoetin from both a medical and a community perspective.

Keywords: anaemia, erythropoietin, chronic lymphocytic leukaemia, non-Hodgkin's lymphoma, multiple myeloma.
Recombinant human Epo (rHuEpo, or epoetin) is remarkably effective and well tolerated in the treatment of anaemic patients with defective production of the endogenous hormone. This is particularly true for uraemia, which represents the prototype of Epo deficiency, so that the treatment of this condition is currently considered the gold standard of epoetin use (Tong \& Nissenson, 2001). Erythropoietin production, however, is reduced in several other conditions, which include anaemia secondary to malignant disorders or as a result of their treatment (Cazzola et al, 1997). Based on a systematic review of the literature, the recent guidelines of the American Society of Clinical Oncology and the American Society of Hematology

Correspondence: Mario Cazzola, MD, Division of Haematology, IRCCS Policlinico S. Matteo, 27100 Pavia, Italy. E-mail: mario.cazzola@unipv.it
(Rizzo et al, 2002) recommend use of epoetin as a treatment option for patients with chemotherapy-associated anaemia with a haemoglobin concentration below $10 \mathrm{~g} / \mathrm{dl}$, and advise subcutaneous administration thrice weekly at a starting dose of $150 \mathrm{U} / \mathrm{kg}$.

Three European trials in the last few years have studied the efficacy of epoetin beta in anaemic patients with multiple myeloma, non-Hodgkin's lymphoma and chronic lymphocytic leukaemia, most of whom were receiving concurrent or recent chemotherapy for their disease (Cazzola et al, 1995; Osterborg et al, 1996, 2002). Despite considerable differences in their designs, all three studies showed that defective endogenous Epo production was a major predictor of response to treatment. In particular, Osterborg et al (2002) demonstrated that epoetin beta treatment was effective in relieving anaemia and improving quality of life in severely anaemic, transfusion-dependent patients with a low serum Epo concentration. These 
observations have reinforced the concept that epoetin treatment is primarily effective in the treatment of endogenous Epo deficiency.

Although effective, the conventional regimen of thriceweekly (t.i.w.) subcutaneous administration of epoetin is costly and cumbersome, and there is a need for improvement (Bunn, 2002). In stable haemodialysis patients, subcutaneous administration of epoetin beta once weekly (q.w.) has been shown to be as safe and effective in maintaining haemoglobin levels as a t.i.w. schedule (Weiss et al, 2000; Locatelli et al, 2002). As regards cancer patients, an uncontrolled, non-randomized, communitybased study employing epoetin alpha at a dose of $40000 \mathrm{IU}$ q.w. has reported improvements in haemoglobin and quality of life similar to the conventional t.i.w. dosing (3 × 10 000 IU) (Gabrilove et al, 2001).

In order to properly assess the effectiveness of a onceweekly dosing regimen in the epoetin treatment of anaemic patients with lymphoproliferative malignancy, we conducted a prospective randomized trial comparing the efficacy and safety of subcutaneous epoetin beta 30000 IU q.w. vs $10000 \mathrm{IU}$ t.i.w. in individuals with evidence of defective endogenous Epo production, as indicated by low serum Epo levels.

\section{PATIENTS AND METHODS}

The present study was an open-label, randomized, parallelgroup, multicentre, phase III trial conducted between September 2000 and December 2001 at 51 centres in 12 countries, promoted and supported by F. Hoffmann-La Roche Ltd, Basel, Switzerland. The design and conduct of the study complied with the ethical principles of good clinical practice, in accordance with the Declaration of Helsinki and local legal requirements. The study was approved by an independent ethics committee at each centre; all patients provided written informed consent before enrolment.

Patients. Adult patients ( $\geq 18$ years) eligible for study inclusion had a histologically confirmed diagnosis of lowgrade non-Hodgkin's lymphoma (NHL), multiple myeloma (MM) or chronic lymphocytic leukaemia (CLL), a Hb level of 9-11 g/dl and a serum Epo level $\leq 100 \mathrm{mU} / \mathrm{ml}$. If systemic anticancer therapy was to be given, it was to continue for at least 4 months from the time of the first study treatment. Patients also had to have a World Health Organization (WHO) performance status grade of $0-2$ and a life expectancy $>6$ months.

Exclusion criteria were: transfusion of red blood cells during the 2 months prior to the study, therapy-resistant hypertension, acute or chronic bleeding requiring treatment in the 3 months prior to study commencement, antitumour therapy in the week before the screening visit (with the exception of corticosteroids and/or low-dose chlorambucil), scheduled bone marrow transplantation during the study period, functional iron deficiency (transferrin saturation $<20 \%$ ) which could not be treated with intravenous (i.v.) iron supplementation prior to the start of study treatment, thrombocytopenia or thrombocytosis (platelet count $<50$ or
$>450 \times 10^{9} / 1$ respectively), vitamin $\mathrm{B}_{12}$ or folic acid deficiencies, haemolysis (haptoglobin <0.30 mg/l), epilepsy, pregnancy, or lactation.

Study procedures. Patients eligible for study inclusion were randomized 1:1 [stratified according to malignancy type, platelet count at screening $\left(<100 \times 10^{9} / \mathrm{l}\right.$, $\left.\geq 100 \times 10^{9} / \mathrm{l}\right)$ and study centre] to receive epoetin beta t.i.w. (10 000 IU per dose) or q.w. (30 000 IU per dose) for 16 weeks, using the $\operatorname{RecoPen}^{\circledR}$ (F. Hoffmann-La Roche, Basel, Switzerland) subcutaneous self-injection delivery system. For patients who failed to respond after 4 weeks of therapy (as indicated by receipt of a blood transfusion in the previous week or an increase in $\mathrm{Hb}$ of $<0.5 \mathrm{~g} / \mathrm{dl}$ vs baseline), the dose of epoetin beta was doubled. Thus, the dose per injection for the t.i.w. group increased to $20000 \mathrm{IU}$ and the dose for the q.w. group increased to $60000 \mathrm{IU}$ (administered as $30000 \mathrm{IU}$ twice weekly). Conversely, if $\mathrm{Hb}$ increased by more than $2 \mathrm{~g} / \mathrm{dl}$ within the same period, the dose of study medication was reduced by $50 \%$. If $\mathrm{Hb}$ exceeded $14 \mathrm{~g} / \mathrm{dl}$, the study medication was suspended until $\mathrm{Hb}$ declined to $\leq 13 \mathrm{~g} / \mathrm{dl}$ when therapy was reinstated at $50 \%$ of the previous dose. Blood transfusions were to be avoided at $\mathrm{Hb}$ levels $>8.5 \mathrm{~g} / \mathrm{dl}$ unless medically indicated, e.g. when marked symptoms related to anaemia such as angina pectoris was present. Haemoglobin was measured at screening, during the first week of therapy and every 2 weeks thereafter.

Enrolled patients with a screening transferrin saturation of $<20 \%$ were to receive i.v. iron supplementation to ensure that adequate iron was rapidly available for erythropoiesis. Following randomization, iron supplementation was also to be performed if the transferrin saturation fell below $20 \%$. The preferred route of administration of supplemental iron was i.v.; however, if this was not possible, then oral iron supplementation was given. Adverse events, haematological parameters, concomitant medications, blood transfusions and antitumour therapy were documented throughout the course of the study.

Efficacy assessments. The primary efficacy variable was the time-adjusted $\mathrm{Hb}$ area under the curve between weeks 5 and $16\left(\mathrm{Hb} \mathrm{AUC}_{5-16}\right)$. The $\mathrm{Hb}$ AUC was determined by the trapezoid rule, and was then divided by the time interval from the first $\mathrm{Hb}$ measurement to the last $\mathrm{Hb}$ measurement between weeks 5 and 16. All available $\mathrm{Hb}$ values were taken into account, whether they were measured at a protocol-specified visit or determined immediately preceding a blood transfusion at non-protocol-specified visits. The $\mathrm{Hb}$ values measured in the 3 weeks following a blood transfusion were replaced by the $\mathrm{Hb}$ value measured immediately before the blood transfusion to correct for the increased $\mathrm{Hb}$ caused by the blood transfusion.

Secondary efficacy parameters included response rate (defined as an increase in $\mathrm{Hb}$ of $\geq 2 \mathrm{~g} / \mathrm{dl}$ vs baseline without blood transfusion in the previous 6 weeks), change in $\mathrm{Hb}$ from baseline, $\mathrm{Hb}$ nadir at 4-week intervals, the percentage of patients with corrected anaemia (Hb nadir $\geq 11$ or $12 \mathrm{~g} / \mathrm{dl}$ ) at 4-week intervals, transfusion-free or severe anaemia-free $(\mathrm{Hb}<8.5 \mathrm{~g} / \mathrm{dl})$ survival, and transfusion requirements (number of patients and units transfused). Various clinical 
parameters were measured with the aim of identifying those predictive of response to epoetin beta. These parameters could be divided into those measured at baseline (serum Epo) and those measured early in the course of treatment [changes in $\mathrm{Hb}$ levels and in soluble transferrin receptor (sTfR) levels].

Laboratory measurements. Blood counts were obtained with the use of automated counters. Circulating Epo levels were measured by a photometric enzyme immunoassay for the quantitative in-vitro determination of human erythropoietin in antibody-precoated microtitre plates (Roche Diagnostics, Mannheim, Germany). The amount of sTfR was estimated by an immunoturbidimetric assay using an automated clinical chemistry analyser (Roche Diagnostics). In order to detect Epo-specific antibodies in serum, the above photometric enzyme immunoassay for the quantitative invitro determination of human Epo was employed, adopting a two-step procedure with a displacement step.

Statistical analysis. We planned to enrol 230 patients with low-grade NHL, MM or CLL that, with an assumed loss-to-follow-up rate of $\sim 20 \%$, would provide 93 patients per treatment arm. This would be sufficient to demonstrate with $80 \%$ power $(\alpha=0.05)$ that epoetin beta administered q.w. is non-inferior to the t.i.w. regimen with respect to the primary efficacy variable.

The primary efficacy variable was analysed for the intentto-treat (ITT) population and the per protocol (PP) population (Table I) was analysed using an analysis of covariance (ANCOVA) model; 'treatment group' was the main factor, with 'underlying malignant disease' and 'baseline $\mathrm{Hb}$ values' as covariates. Based on the least squares means and the corresponding standard errors of the ANCOVA model, 90\% and 95\% confidence intervals were calculated for the difference in $\mathrm{Hb}$-AUCs between the two treatment groups at a significance level of $5 \%$.

The time to first response was analysed using the logrank test, adjusted for underlying malignant disease. The response curves were estimated using Kaplan-Meier techniques. Transfusion-free or severe anaemia-free survival was analysed using a Cox proportional hazard model, adjusted for the type of underlying malignant disease at a significance level of $5 \%$ (Wald $\chi^{2}$ test). The rate of failure was defined as the first date with $\mathrm{Hb}<8.5 \mathrm{~g} / \mathrm{dl}$, a blood transfusion or death. Kaplan-Meier methods were used to estimate the transfusion-free or severe anaemia-free survival curves. Transfusion requirements were compared between treatment groups with the Cochrane-MaentelHaenzel test, unadjusted and adjusted for underlying malignant disease.

The change from baseline to final $\mathrm{Hb}$ value and the $\mathrm{Hb}$ nadir in any 4-week interval was analysed separately using ANCova models with the main factor 'treatment group', and 'underlying malignant disease' and 'baseline $\mathrm{Hb}$ value' as covariates. The influence of various clinical parameters on response was analysed using Cox's proportional hazard models.

\section{RESULTS}

Of a total of 322 patients screened for serum Epo, 241 were found of have levels $\leq 100 \mathrm{mU} / \mathrm{ml}$ (Table I): these subjects were enrolled into the study and randomized to the two treatment groups (q.w., $n=119$; t.i.w., $n=122$ ). There were no major differences in the demographic and baseline clinical characteristics of the two treatment groups (Table II). Multiple myeloma was the predominant tumour type in both groups $(\sim 70 \%)$. The vast majority of patients were receiving concurrent chemotherapy or had received recent chemotherapy for their disease: only $6 / 237$ (2.5\%) subjects did not receive chemotherapy before or during the study. In total, 22 patients $(9 \%)$ were withdrawn from the study (q.w., $n=14$; t.i.w., $n=8$ ). The main reasons for withdrawal were death $(n=12)$, adverse events $(n=4)$ and refusal of treatment $(n=4)$.

Increase in haemoglobin over time

Mean baseline $\mathrm{Hb}$ values at the start of study treatment were similar for both groups (Table II). The change in $\mathrm{Hb}$ level over time is depicted in Fig 1. Following 8 weeks of treatment, median changes in $\mathrm{Hb}$ were $>2 \mathrm{~g} / \mathrm{dl}$ in both

Table I. Patient distribution into the study populations.

\begin{tabular}{llll}
\hline Study population & $\begin{array}{l}\text { Serum } \\
\text { Epo }>100 \mathrm{mU} / \mathrm{ml}, n\end{array}$ & $\begin{array}{l}\text { Serum } \\
\text { Epo } \leq 100 \mathrm{mU} / \mathrm{ml}, n\end{array}$ \\
\hline Screened for serum Epo $(n=322)$ & 81 & 241 & \\
& & Once-weekly (q.w.), $n$ & Thrice-weekly (t.i.w.), $n$ \\
Randomized $(n=241)$ & - & 119 & 122 \\
Safety $(n=237)^{*}$ & - & 118 & 119 \\
Intent to treat $(n=229) \dagger$ & - & 115 & 114 \\
Per protocol $(n=205) \dagger$ & - & 101 & 104 \\
\end{tabular}

*Four patients were excluded from the safety population (q.w., $n=1$; t.i.w., $n=3$ ) as they did not receive epoetin beta. $\dagger$ Eight patients were excluded from the intent-to-treat population (q.w., $n=3$; t.i.w., $n=5$ ) as they had only one Hb level measured between weeks 5 and 16 .

$\$$ Twenty-four patients were excluded from the per protocol population for violations of the study criteria (q.w., $n=14$; t.i.w., $n=10)$. 
Table II. Patient demographics and baseline characteristics (safety population).

\begin{tabular}{lll}
\hline & $\begin{array}{l}\text { Once weekly } \\
(n=118)\end{array}$ & $\begin{array}{l}\text { Three-times weekly } \\
(n=119)\end{array}$ \\
\hline Sex, n (\%) & & \\
$\quad$ Male & $55(47)$ & $47(39)$ \\
Female & $63(53)$ & $72(61)$ \\
Age, years; median (range) & $67(38-82)$ & $65(33-90)$ \\
Body weight, kg, mean \pm SD & $68 \cdot 6 \pm 12 \cdot 3$ & $66 \cdot 9 \pm 13 \cdot 8$ \\
Tumour classification & & \\
MM & $78(66)$ & $80(67)$ \\
$\quad$ NHL & $16(14)$ & $16(14)$ \\
$\quad$ CLL & $24(20)$ & $10 \cdot 1 \pm 1 \cdot 0$ \\
Haemoglobin $(\mathrm{g} / \mathrm{dl})$, mean \pm SD & $10 \cdot 2 \pm 1 \cdot 0$ & $41(6-97)$ \\
Serum Epo $(\mathrm{mU} / \mathrm{ml}) ;$ median (range) & $41(5-97)$ & $223(1-1820)$ \\
Serum ferritin $(\mu \mathrm{g} / \mathrm{l}) ;$ median (range) & $245(12-1342)$ & $38 / 119(32)$ \\
No chemotherapy prior to epoetin beta therapy & $39 / 118(33)$ & $19 / 119(16)$ \\
No chemotherapy concurrent with epoetin beta therapy & $13 / 118(11)$ & $4 / 119(3)$ \\
No chemotherapy at all & $2 / 118(2)$ & \\
\hline
\end{tabular}

CLL, chronic lymphocytic leukaemia; MM, multiple myeloma; NHL, non-Hodgkin's lymphoma.

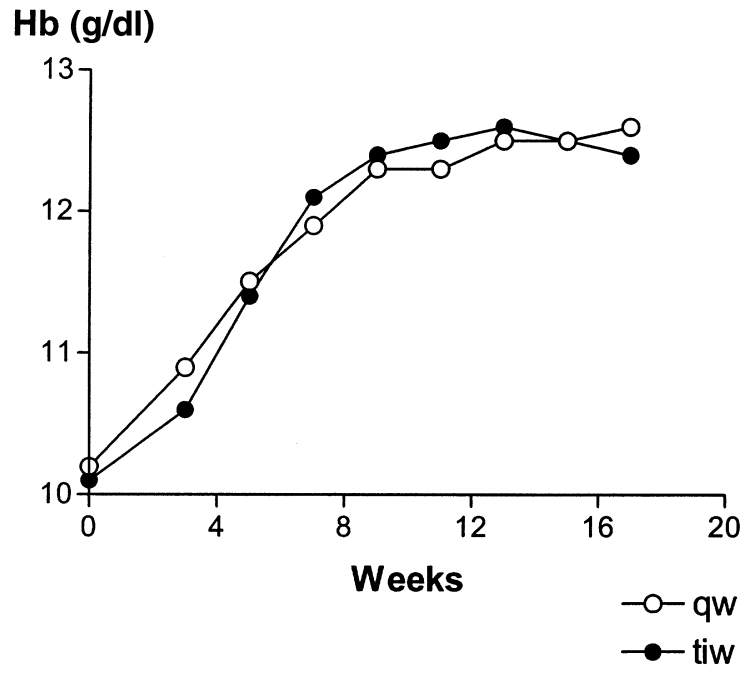

Fig 1. Time course of mean haemoglobin $(\mathrm{Hb})$ level in anaemic patients with lymphoproliferative malignancies treated with epoetin beta 30000 IU q.w. $(n=101)$ or 10000 IU t.i.w. $(n=104)(\mathrm{PP}$ population).

treatment groups; the difference between the groups was $\sim 0 \cdot 2 \mathrm{~g} / \mathrm{dl}$ at any time point.

The time-adjusted $\mathrm{Hb} \mathrm{AUC}_{5-16}$ was calculated for each patient in both treatment groups from the PP population. The median $\mathrm{Hb}^{-\mathrm{AUC}_{5-16}}$ was similar in both groups (differences $\sim 0 \cdot 2-0 \cdot 3 \mathrm{~g} / \mathrm{dl}$ ). ANCOVA confirmed that the median estimates of $\mathrm{Hb}-\mathrm{AUC}_{5-16}$ were similar between the q.w. and t.i.w. groups $(12 \cdot 05$ vs $12 \cdot 27 \mathrm{~g} / \mathrm{dl})$ with the overall difference being $0 \cdot 22[-0 \cdot 53,0 \cdot 10,90 \%$ confidence interval (CI)]. Differences between the t.i.w. and q.w. groups did not exceed $0.6 \mathrm{~g} / \mathrm{dl}$ at any time. These data were confirmed when the analysis was performed on the
ITT population. The differences in the $\mathrm{Hb}-\mathrm{AUC}_{5-16}$ between the two treatment groups were similar across the three types of lymphoproliferative malignancies investigated (Table III).

Response rate and time to response The proportion of patients who responded to treatment was similar in both groups (72 vs $75 \%$ for q.w. vs t.i.w. dosing, ITT population). Median time to response was $71 \mathrm{~d}$ for the q.w. group and $57 \mathrm{~d}$ for the t.i.w. group $(P=0.57)$.

Haemoglobin nadirs and correction of anaemia

Mean $\mathrm{Hb}$ nadir values were determined over 4-week intervals and are presented in Fig 2 (ITT population). Values were similar for both groups throughout the study period. Confidence intervals $(90 \%)$ were largely within the range of -0.5 to +0.5 , ruling out the possibility of a significant difference between treatment groups.

Correction of anaemia (defined as a $\mathrm{Hb}$ nadir $\geq 11$ or $\geq 12 \mathrm{~g} / \mathrm{dl}$ in a 4-week interval) was achieved in $79 \%$ and $81 \%$ of patients $(\mathrm{Hb} \geq 11 \mathrm{~g} / \mathrm{dl})$ and $60 \%$ and $64 \%$ of patients $(\mathrm{Hb} \geq 12 \mathrm{~g} / \mathrm{dl})$ in the q.w. and t.i.w. groups respectively (ITT population).

\section{Blood transfusions}

Mean $\mathrm{Hb}$ values before blood transfusion were the same for both groups $(7 \cdot 4 \mathrm{~g} / \mathrm{dl})$, and the overall incidence of transfusion in the study was low (11\% of patients). The percentage of patients receiving at least one transfusion was marginally lower in the q.w. group (9\%) compared with the t.i.w. group (14\%) but this difference was not significant (Cochrane-Maentel-Haenzel test, $P=0 \cdot 14$ adjusted for underlying disease).

Analysis of transfusion-free or severe anaemia-free survival confirmed that the number of patients requiring transfusions was low and that the rates were similar 
Table III. Change in the area under the haemoglobin-time curve between weeks 5 and 16 (Hb-AUC $\left.{ }_{5-16}\right)$ in anaemic patients with lymphoproliferative malignancies treated with epoetin beta 30000 IU q.w. or 10000 IU t.i.w. (per protocol population).

\begin{tabular}{llll}
\hline & \multicolumn{2}{l}{ Mean Hb-AUC $(\mathrm{g} / \mathrm{dl})$} & \\
\cline { 2 - 3 } & $30000 \mathrm{IU}$ q.w. & $10000 \mathrm{IU}$ t.i.w. & Difference $(90 \% \mathrm{CI})$ \\
\hline Total population* & $12 \cdot 05$ & $12 \cdot 27$ & $-0 \cdot 22(-0 \cdot 53,0 \cdot 10)$ \\
Multiple myeloma $\dagger$ & $12 \cdot 11$ & $12 \cdot 25$ & $-0 \cdot 14(-0 \cdot 49,0 \cdot 21)$ \\
Non-Hodgkin's lymphoma $\dagger$ & $11 \cdot 51$ & $12 \cdot 13$ & $-0 \cdot 62(-1 \cdot 81,0 \cdot 56)$ \\
Chronic lymphocytic leukaemia $\dagger$ & $12 \cdot 32$ & $12 \cdot 54$ & $-0 \cdot 21(-1 \cdot 03,0 \cdot 61)$ \\
\hline
\end{tabular}

*Per protocol (PP) population.

$\dagger$ Intent-to-treat (ITT) population.

CI, confidence interval.

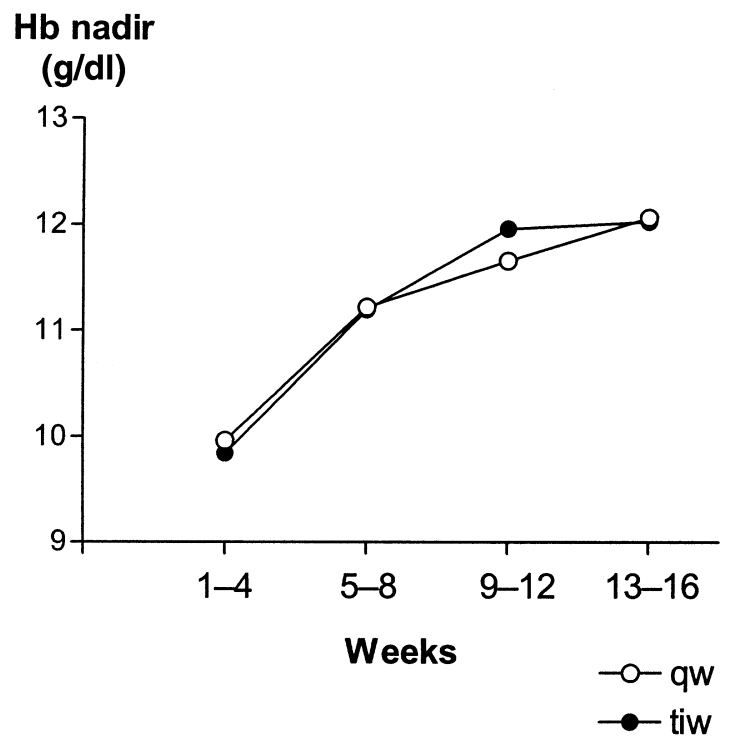

Fig 2. Mean haemoglobin $(\mathrm{Hb})$ nadir at 4-weekly intervals in anaemic patients with lymphoproliferative malignancies treated with epoetin beta 30000 IU q.w. $(n=115)$ or 10000 IU t.i.w. $(n=114)$ (ITT population).

between the two groups (Cox regression analysis adjusted for underlying malignant disease, $P=0.50$ ).

Epoetin beta doses, iron supplementation and safety

The mean weekly epoetin beta dose between weeks 5 and 16 was $323 \mathrm{IU} / \mathrm{kg}$ in the once-weekly group and $267 \mathrm{IU} / \mathrm{kg}$ in the thrice-weekly group (ITT). Therefore, the onceweekly to thrice-weekly dose ratio during this period was $1 \cdot 21$ (95\% CI $0 \cdot 90 ; 1 \cdot 61)$. The observed difference could be attributed to the small CLL subgroup (24 vs 24 patients, ratio $2 \cdot 29$ ), while no difference was observed in the majority of patients with multiple myeloma or NHL (95 vs 98 patients, ratio $1 \cdot 02$ ). The difference observed in the small CLL subgroup was determined by the fact that a few patients receiving epoetin beta thrice weekly achieved a response quickly, which was maintained with low doses of the drug.
Overall, there was a decrease in the median and mean weekly dose per $\mathrm{kg}$ in both treatment groups by week 8 to the end of the study in both the PP and the ITT population.

Similar proportions of patients needed i.v. (44\% vs 39\%) and oral $(75 \%$ vs $67 \%)$ iron supplementation in the q.w. and the t.i.w. group respectively.

Treatment with epoetin beta was well tolerated. Eightyfour patients $(71 \%)$ in each treatment group reported at least one adverse event. Only 12 patients (10\%) in the q.w. and 22 patients $(18 \%)$ in the t.i.w. group were considered to have treatment-related adverse events. The most common adverse events for the q.w. and t.i.w. groups were infections (37\% vs 38\%), gastrointestinal disorders (31\% vs 31\%), general disorders (16\% vs $18 \%)$ and vascular disorders (15\% vs 18\%).

Evaluation of anti-Epo antibodies was planned at baseline and during week 17 of study. All of the 118 patients in the once-weekly group and 119 in the thrice-weekly group that were analysed were negative for antiepoetin beta antibodies.

Predictors and early indicators of response to epoetin beta Both baseline clinical parameters and changes in clinical parameters early in the study period were assessed for predictive power of response to epoetin beta. At baseline, serum Epo level $(P=0.002)$ was found to be predictive of response (Table IV). Changes in $\mathrm{Hb}$ between weeks 1 and 3 $(P<0.00001)$, and changes from baseline in sTfR levels in weeks 2 and $3(P<0 \cdot 01)$ were found to be early indicators of response.

\section{DISCUSSION}

This study is the first to investigate the relative efficacy and safety of q.w. and t.i.w. epoetin regimens in a powered comparison. Its results demonstrate that epoetin beta given once weekly is as effective and well tolerated as a threetimes-weekly schedule in treating anaemic patients with lymphoproliferative disorders and reduced endogenous Epo production.

The current study was designed to test the hypothesis that epoetin beta given once weekly was not inferior to the 
Table IV. Baseline predictors and early treatment indicators of response to epoetin beta.

\begin{tabular}{llc}
\hline & Hazard ratio $(95 \% \mathrm{CI})$ & $P$-value \\
\hline Baseline & & \\
$\quad$ Haemoglobin, g/dl & $0 \cdot 884(0 \cdot 756-1 \cdot 035)$ & $0 \cdot 125$ \\
$\quad \begin{array}{l}\text { Serum creatinine, mmol/l } \\
\quad \text { Serum Epo }(\mathrm{mU} / \mathrm{ml})\end{array}$ & $1 \cdot 000(0 \cdot 996-1 \cdot 003)$ & $0 \cdot 881$ \\
Early treatment & $0 \cdot 989(0 \cdot 982-0 \cdot 996)$ & $0 \cdot 002$ \\
$\quad$ Hb increase from week 1-3 $(0 \cdot 1 \mathrm{~g} / \mathrm{dl})$ & $1 \cdot 053(1 \cdot 038-1 \cdot 069)$ & $<0 \cdot 00001$ \\
$\quad$ sTfR level increase from baseline & & \\
$\quad>15 \%$ vs $\leq 15 \%$ & $1 \cdot 604(1 \cdot 137-2 \cdot 265)$ & $0 \cdot 007$ \\
$\quad>20 \%$ vs $\leq 20 \%$ & $1 \cdot 635(1 \cdot 178-2 \cdot 270)$ & $0 \cdot 003$ \\
$\quad>25 \%$ vs $\leq 25 \%$ & $1 \cdot 695(1 \cdot 238-2 \cdot 322)$ & $0 \cdot 001$ \\
\hline
\end{tabular}

sTfR, soluble transferrin receptor.

three-times weekly schedule with respect to several important clinical parameters. The primary efficacy parameter of the study was the time-adjusted area under the $\mathrm{Hb}$-time curve $\left(\mathrm{Hb} \mathrm{AUC}_{5-16}\right)$. The q.w. regimen was clinically comparable to the t.i.w. regimen, as the two curves were virtually identical. Furthermore, the difference in $\mathrm{Hb}$ $\mathrm{AUC}_{5-16}$ between the two groups did not exceed $0.6 \mathrm{~g} / \mathrm{dl}$ at any time during the study. The remaining clinical parameters examined in this study ( $\mathrm{Hb}$ nadirs, response rates and transfusion requirements) confirmed these data. In the assessment of equivalence in mean weekly epoetin doses, a difference of $21 \%$ (once-weekly to thrice-weekly dose ratio equal to $1 \cdot 21$ ) was recorded between the two treatment groups between weeks 5 and 16. This ratio remained within the prespecified equivalence range. Moreover, the observed difference could be attributed to a small portion of patients with CLL who responded quickly to epoetin beta administered thrice weekly. No difference at all (i.e. $2 \%$ ) was observed in the vast majority of patients $(n=193)$ with multiple myeloma or NHL.

A previous study has examined the effect of a onceweekly epoetin regimen on $\mathrm{Hb}$ levels, transfusion requirements and quality of life in patients with solid and haematological malignancies (Gabrilove et al, 2001). This study showed that a dose of $40000 \mathrm{IU}$ once weekly provided improvements in haemoglobin and quality of life similar to the conventional thrice weekly dosing $(3 \times 10000 \mathrm{IU})$. However, this study had many potential flaws (Nguyen \& Trinh 2002): (a) it was non-randomized and compared the once-weekly results with those of historical, rather than parallel, control subjects receiving epoetin t.i.w.; (b) there was no adjustment for potential baseline confounding variables and for handling of the relatively large dropout rate; (c) different weekly doses of epoetin alpha (40 000 in q.w. group vs 30000 in t.i.w. group) were compared. In contrast, the current study was randomized, and directly compared results between patients receiving identical doses of epoetin beta (30 $000 \mathrm{IU}$ ) q.w. or t.i.w., thus producing a more robust assessment. The results are consistent with those of recent randomized trials of epoetin beta in the maintenance treatment of renal anaemia, which demonstrated that the efficacies of once weekly and three times weekly epoetin beta regimens are equivalent (Weiss et al, 2000; Locatelli et al, 2002).

The efficacy of the once-weekly regimen is in agreement with the physiological role of Epo in erythropoiesis. In fact, Epo mainly acts as a survival factor for erythroid progenitors, which require the continual presence of small doses of the hormone to survive (Koury \& Bondurant, 1990a; Kelley et al, 1993). In this model of erythropoiesis based on Epo prevention of programmed cell death, erythropoiesis can be substantially and steadily expanded only through preamplification of Epo-dependent progenitors (Koury \& Bondurant, 1990b). When endogenous Epo levels are inappropriately low, administration of epoetin can be effective in allowing the survival of more erythroid progenitors and the generation of erythroid precursors that subsequently mature to red cells. The results of the present study indicate that this can be effectively achieved with the once-weekly subcutaneous administration of epoetin beta.

Despite the success of epoetin in treating anaemia in both the haemodialysis and cancer settings, outside the setting of uraemia, a variable portion of patients do not respond to epoetin therapy (Cazzola et al, 1997). Attempts have been made to identify those patients most likely to respond to therapy. In this study, the number of patients who responded to epoetin beta treatment was high in both arms $(\sim 75 \%)$. This is probably attributable to the strict inclusion criteria of the trial, whereby only patients with defective endogenous Epo production, as indicated by serum Epo levels $\leq 100 \mathrm{mU} / \mathrm{ml}$, were enrolled. In clinical practice, a serum Epo level $<100 \mathrm{mU} / \mathrm{ml}$ in an anaemic patient can be taken as an indicator of reduced serum Epo production and a strong predictor of response to epoetin treatment (Beguin, 2002). It must be stressed that, even in this selected population of patients with low serum Epo, this latter parameter was found to be a strong predictor of response (Table IV). This also indicates that, in patients with defective endogenous Epo production, the lower the serum Epo, the higher the likelihood of response.

Tailoring epoetin use to patients with a high probability of response, i.e. improving the prediction of response, is one of the major ways of making epoetin treatment costeffective (Barosi \& Marchetti, 2000). Therefore, in patients 
with lymphoproliferative disorders, limiting epoetin administration to those who show defective endogenous Epo production represents a rational use of the recombinant hormone from both a medical (Pangalis et al, 2002) and community perspective (Barosi \& Marchetti, 2000). In this study, for instance, about $25 \%$ of patients initially screened for serum Epo had values $>100 \mathrm{mU} / \mathrm{ml}$ (Table I) and were excluded from treatment. A small portion of patients, however, in spite of their low serum Epo levels $(<100 \mathrm{mU} / \mathrm{ml})$, did not respond to epoetin beta: further characterization of predictors of non-response is required as this might further improve the cost effectiveness of epoetin therapy.

Incidences of adverse events during the study were similar for both regimens, and the incidence of those that could be directly related to epoetin beta was very low. More importantly, no patient enrolled in the study developed antiEpo antibodies. It has recently been noted that some dialysis patients treated with epoetin have developed pure red cell aplasia through the production of neutralizing anti-Epo antibodies (Casadevall et al, 2002). This complication appears to be linked to a particular epoetin formulation (Gershon et al, 2002), and whether it can also occur outside nephrology is unclear at present. A close laboratory monitoring of patients receiving epoetin therapy is, therefore, recommended (Cavill \& Williams, 2002).

In conclusion, epoetin beta given q.w. is comparable to the established t.i.w. regimen and, therefore, represents an effective and safe treatment for anaemia in patients with lymphoproliferative malignancy and defective endogenous Epo production. Self-administration at home of the same quantity of epoetin beta in a single weekly injection with no loss of efficacy will undoubtedly help to produce substantial cost savings (Besarab et al, 2002). Using this method of administration and tailoring treatment to subjects with defective endogenous Epo production represents a rational use of epoetin from a medical and a community perspective.

\section{ACKNOWLEDGMENT}

This study was supported by F. Hoffmann-La Roche Ltd, Basel, Switzerland.

\section{REFERENCES}

Barosi, G. \& Marchetti, M. (2000) The clinical utility of epoetin in cancer patients: a matter of perspective. Haematologica, 85, 449450.

Beguin, Y. (2002) Prediction of response and other improvements on the limitations of recombinant human erythropoietin therapy in anemic cancer patients. Haematologica, 87, 1209-1221.

Besarab, A., Reyes, C.M. \& Hornberger, J. (2002) Meta-analysis of subcutaneous versus intravenous epoetin in maintenance treatment of anemia in hemodialysis patients. American Journal of Kidney Disease, 40, 439-446.

Bunn, H.F. (2002) Drug-induced autoimmune red-cell aplasia. New England Journal of Medicine, 346, 522-523.

Casadevall, N., Nataf, J., Viron, B., Kolta, A., Kiladjian, J.J., MartinDupont, P., Michaud, P., Papo, T., Ugo, V., Teyssandier, I., Varet, B. \& Mayeux, P. (2002) Pure red-cell aplasia and anti- erythropoietin antibodies in patients treated with recombinant erythropoietin. New England Journal of Medicine, 346, 469-475.

Cavill, I. \& Williams, J.D. (2002) Benefits of recombinant human erythropoietin. Lancet, 360, 1606-1607.

Cazzola, M., Mercuriali, F. \& Brugnara, C. (1997) Use of recombinant human erythropoietin outside the setting of uremia. Blood, 89, 4248-4267.

Cazzola, M., Messinger, D., Battistel, V., Bron, D., Cimino, R., EnllerZiegler, L., Essers, U., Greil, R., Grossi, A. \& Jager, G. (1995) Recombinant human erythropoietin in the anemia associated with multiple myeloma or non-Hodgkin's lymphoma: dose finding and identification of predictors of response. Blood, 86, 44464453.

Gabrilove, J.L., Cleeland, C.S., Livingston, R.B., Sarokhan, B., Winer, E. \& Einhorn, L.H. (2001) Clinical evaluation of onceweekly dosing of epoetin alfa in chemotherapy patients: improvements in hemoglobin and quality of life are similar to threetimes-weekly dosing. Journal of Clinical Oncology, 19, 2875-2882.

Gershon, S.K., Luksenburg, H., Cote, T.R. \& Braun, M.M. (2002) Pure red-cell aplasia and recombinant erythropoietin. New England Journal of Medicine, 346, 1584-1586.

Kelley, L.L., Koury, M.J., Bondurant, M.C., Koury, S.T., Sawyer, S.T. \& Wickrema, A. (1993) Survival or death of individual proerythroblasts results from differing erythropoietin sensitivities: a mechanism for controlled rates of erythrocyte production. Blood, 82, 2340-2352.

Koury, M.J. \& Bondurant, M.C. (1990a) Erythropoietin retards DNA breakdown and prevents programmed death in erythroid progenitor cells. Science, 248, 378-381.

Koury, M.J. \& Bondurant, M.C. (1990b) Control of red cell production: the roles of programmed cell death (apoptosis) and erythropoietin. Transfusion, 30, 673-674.

Locatelli, F., Baldamus, C.A., Villa, G., Ganea, A. \& Martin de Francisco, A.L. (2002) Once-weekly compared with three-timesweekly subcutaneous epoetin beta: results from a randomized, multicenter, therapeutic-equivalence study. American Journal of Kidney Disease, 40, 119-125.

Nguyen, T.V. \& Trinh, G.N. (2002) Clinical evaluation of onceweekly and three-times-weekly dosings of epoetin alfa in chemotherapy patients: problems of study design and interpretation. Journal of Clinical Oncology, 20, 878.

Osterborg, A., Boogaerts, M.A., Cimino, R., Essers, U., Holowiecki, J., Juliusson, G., Jager, G., Najman, A. \& Peest, D. (1996) Recombinant human erythropoietin in transfusion-dependent anemic patients with multiple myeloma and non-Hodgkin's lymphoma: a randomized multicenter study. The European Study Group of Erythropoietin (Epoetin Beta) Treatment in Multiple Myeloma and Non-Hodgkin's Lymphoma. Blood, 87, 26752682.

Osterborg, A., Brandberg, Y., Molostova, V., Iosava, G., Abdulkadyrov, K., Hedenus, M. \& Messinger, D. (2002) Randomized, double-blind, placebo-controlled trial of recombinant human erythropoietin, epoetin Beta, in hematologic malignancies. Journal of Clinical Oncology, 20, 2486-2494.

Pangalis, G.A., Siakantaris, M.P., Angelopoulou, M.K., Vassilakopoulos, T.P., Dimopoulou, M.N., Kyrtsonis, M.C., Konstantopoulos, K., Tsaftaridis, P., Vaiopoulos, G.A. \& Kontopidou, F.N. (2002) Downstaging Rai stage III B-chronic lymphocytic leukemia patients with the administration of recombinant human erythropoietin. Haematologica, 87, 500-506.

Rizzo, J.D., Lichtin, A.E., Woolf, S.H., Seidenfeld, J., Bennett, C.L., Cella, D., Djulbegovic, B., Goode, M.J., Jakubowski, A.A., Lee, S.J., Miller, C.B., Rarick, M.U., Regan, D.H., Browman, G.P. \& Gordon, M.S. (2002) Use of epoetin in patients with cancer: evidence- 
based clinical practice guidelines of the American Society of Clinical Oncology and the American Society of Hematology. Blood, 100, 2303-2320.

Tong, E.M. \& Nissenson, A.R. (2001) Erythropoietin and anemia. Seminars in Nephrology, 21, 190-203.

Weiss, L.G., Clyne, N., Divino Fihlho, J., Frisenette-Fich, C., Kurkus, J. \& Svensson, B. (2000) The efficacy of once weekly compared with two or three times weekly subcutaneous epoetin beta: results from a randomized controlled multicentre trial. Swedish Study Group. Nephrology, Dialysis and Transplantation, 15, 2014-2019.

\section{APPENDIX}

In addition to the authors of the present paper, the following investigators participated in the NeoRecormon ${ }^{\circledR}$ OnceWeekly (NOW) study: Johannes Ach (Wien), Photis Beris (Geneve), Réda Bouabdallah (Marseille), Dominique Bron (Brussels), Po-Min Chen (Taipei), Chang-Fang Chiu (Taichung), Guenther Derigs (Mainz), Anna Dmoszynska (Lublin), Houchingue Eghbali (Bordeaux), Gerlinde Egerer
(Heidelberg), Andreas Engert (Koeln), Thierry Facon (Lille), Guenther Gastl (Innbruck), Christian Gisselbrecht (Paris), Alberto Grossi (Florence), Corinne Haioun (Creteil), Andrzej Hellmann (Gdansk), Raoul Herbrecht (Strasbourg), Ulrich G. Jaeger (Wien), Ladislav Jebavy (Hradec Hralove), Saengsuree Jootar (Bangok), Tomas Kozak (Prague), Tibor Kovacsovics (Lausanne), Pierre Lederlin (Vandoevre-LesNancy), Pietro Leoni (Ancona), Werner Linkesch (Graz), Hajna Losonczy (Pecs), Franco Mandelli (Rome), Jiri Mayer (Brno), Noel Milpied (Nantes), Wichean Mongkonsritragoon (Bangok), Pierre Morel (Lens), Mohamed R. Nouwrousian (Essen), Christian Peschel (Muenchen), Tadeusz Robak (Lodz), Malgorzata Rokicka-Piotrowicz (Warsaw), JeanFrançois Rossi (Montpellier), András Rosta (Budapest), Stefano Sacchi (Modena), Johann Schueller (Wien), LeeYung Shih (Taipei), Noppadol Siritanaratkul (Bangok), Hans Tesch (Villingen-Schwenningen), Hervé Tilly (Rouen), Seppo Vanhatalo (Pori), Pierre Zachee (Antwerpen), Pierluigi Zinzani (Bologna). 